\title{
Experiencing Public Parks through Phenomenology: Case of Riffa Walk Park, Bahrain
}

\author{
Sandra Rachel Anil Job, Islam Hamdi Elghonaimy* \\ Department of Architecture and Interior Design, College of Engineering, University of Bahrain, Bahrain
}

Received January 16, 2021; Revised June 25, 2021; Accepted October 20, 2021

\section{Cite This Paper in the following Citation Styles}

(a): [1] Sandra Rachel Anil Job, Islam Hamdi Elghonaimy, "Experiencing Public Parks through Phenomenology: Case of Riffa Walk Park, Bahrain," Civil Engineering and Architecture, Vol. 10, No. 1, pp. 224 - 235, 2022. DOI: 10.13189/cea.2022.100119.

(b): Sandra Rachel Anil Job, Islam Hamdi Elghonaimy (2022). Experiencing Public Parks through Phenomenology: Case of Riffa Walk Park, Bahrain. Civil Engineering and Architecture, 10(1), 224 - 235. DOI: 10.13189/cea.2022.100119.

Copyright $\odot 2022$ by authors, all rights reserved. Authors agree that this article remains permanently open access under the terms of the Creative Commons Attribution License 4.0 International License

\begin{abstract}
Human beings experience the world with a natural attitude, which is often due to everyday habitual experiences. These everyday experiences require being 'in place'. It is known that the visual sense is highly dominant over other senses. By representing virtual images of architecture, which cannot be distinguished from reality, sensorial experience in spaces has been lost and has become meaningless. By introducing sensual bodily experiences in places, one can come across meaningful spatial and bodily experiences inside and outside the built environment. Senses like sight, hearing, touch, and even smell contribute to the spatial experience and pleasure. An approach that emphasizes multi-senses will not alienate people from experiencing a space. This research intends to investigate the bodily experiences within an urban place. Further, the behavioural patterns, noise levels, and issues that persist within the place are observed and recommendations are given for fostering a complete spatial experience within the site.
\end{abstract}

Keywords Phenomenology, Sense of Place, Bodily Experiences, Urban Place, Human Senses

\section{Introduction}

As is well known, the architecture in cities reflects the cultural, social, political, and economic conditions of civilizations. Moving and walking in cities is interesting for researchers to analyse the feeling of spaces and the visual quality in cities. While moving within the streets, you can observe the changing of the city's urban state, the impacts upon urban patterns and the architectural features. It is easy to differentiate between the architecture of buildings through various decades. In addition, it defined the development of cities and the common changes in life for people within the building volumes, forms, colour, height, and design [1]. In the last few decades, the image of dealing with designing open spaces in Cities in the Arab region, in general, has changed. While observing open spaces in Bahrain, the visitors can recognize the significant periods of Bahrain civilizations, during the last decade, the urban habitat in Bahrain. These spaces are witness to economic, political, and social changes. Open spaces are an intrinsic part of our existence, the use of the concept of Phenomenology in designing such open spaces ought to enhance the visual quality of cities and view it as a mirror that reflects not only how others see us but also how we see and value our inner self [2].

\subsection{Concept of Phenomenology}

Phenomenology, in simple words, can be defined as the study of human experiences. Phenomenology was established as philosophy by Edmund Husserl. Phenomenology is also known as the study of consciousness and subjectivity [3]. Edmund Husserl wanted to put forwards a new method of philosophy that would give certainty to a civilization that is in decline. Having said 
that, apart from Edmund Husserl, there exist other prominent academicians associated with phenomenology as well. Some of them are Martin Heidegger, Alfred Schultz and Maurice Merleau-Ponty. There exist different concepts within phenomenology such as Phenomenon of life or wholeness, Phenomenology of Architecture, Phenomenology of the Senses, Phenomenology of Place and so on. Christopher Alexander's Phenomenon of Wholeness comprises different aspects of his idea of wholeness and architecture, which includes nature of the order, wholeness, patterns, geometry, and so on [4]. The author uses a concept of a pattern language to justify his phenomenology of environmental wholeness. He explains how by coherence, there is harmony in a place which is being filled, thus touching lives. His idea explains that where wholeness exists, there exists life. Thus, enabling wellbeing, beauty and so on. Understanding his concept of wholeness is crucial. Several elements can play a role in justifying wholeness, which includes pictures, drawings, colours, etc. He argues that one can achieve a sense of life through trial and error or a sense of wholeness. Interestingly, he also considers 15 properties that contribute to his pattern language to understand wholeness. Some of them include roughness, void, echoes, etc. These patterns together help to interweave a positive space creating wholeness within that boundary [5].

On the other hand, Christian Norbert Schultz's philosophy is about protective spirits around objects, spirits of place, and so on. He elaborates on the idea of existential space and expresses the relationship between man and the environment. His idea came into existence based on an ancient concept of "genius loci," which refers to a protective spirit of an object. This concept helps to give an existential feeling about a place or life. He highlights that a place becomes a dwelling when people live in it. Thus, achieving meaningful architecture than creating modernist buildings which don't express meaning to the person dwelling inside them. His concept is also applied to natural landscapes and their relation to a building. It is suggested that a building must be designed in such a way that it blends with the landscape, where each of the landscapes has its own identity, similar to the phenomenology of place. The core idea is linked to humans, as humans have a root in their landscapes. The author also helps to achieve this using 5 themes: thing, order, character, light, and time to create meaningful architecture [6].

Before discussing the phenomenology of the senses and bodily experiences, it is crucial to address the phenomenology of place, environment, and architecture. Though the concept is not specifically related to place, it includes the relationship between environment and architecture. According to Seamon [7], humans and the environment constitute an 'indivisible whole'. The author explains radical empiricism, which is also experience. Phenomenology is interpreted as the study of human experience, where the person is in a constant relationship with the environment. He describes how the phenomenology of cerebral structures relates to lifting an experience. He also explains phenomenology as the study and description of an occurrence. The author explains how phenomenology can be light, colour, architecture, landscape, place, home, travel, seeing, learning, blindness, jealousy, etc. Human beings play a prominent role as they experience this in their environments. He also describes how phenomenology focuses on how a person exists concerning their world.

\subsection{Phenomenology of the Bodily Experiences}

Eyes of the Skin is a fundamental book by Juhanni Pallasma that revolves around the idea of multisensorial spatial experiences. It discusses a crucial yet essential part of architecture that is often neglected. He discusses how to create multi-sensorial spatial experiences. According to Pallasmaa, we often give more importance to factors such as visual perception in such a way that it dominates every other sense. Moreover, he explains the value of different senses and together how it can create a spatial experience. Architects and architecture play a role in achieving this experience [8]. It could be achieved by the materials, the location, its relationship with the existing nature, and so on. He also states that this can affect human thoughts and the way they feel about things and hence can change the way they live. Hence, it is essential to study and identify the meanings that alter our everyday experiences in urban places as one constantly spends their time in relation to the environment. He states that meanings cannot be invented, and they are existential [9].

\subsection{Research Issue}

Though we experience places on a daily basis, we don't realize that we consciously sense our environments, which further alter our behaviour, movement, and experiences within a place. Architecture and Urban designs are revolved primarily around the visual senses today, losing the sense of place. This research intends to study literature that uncovers phenomenology in places and how our bodily experiences can be altered by the senses. Further, key methodology is identified to experience an urban place from relevant literature.

\subsection{Literature Review}

The role of the bodily is considered as a starting point and anchor to the perpetual experience [10]. This idea is often neglected by traditions in philosophies and considered superficially. In addition, Lam introduces the idea of the mind along with the body. She states that mind and body are not separate [11]. She highlights that they form the totality of one body that embodies the world together.

Ponty, on the other hand, considers the idea of "me", where its mental aspects are embedded with the body [10]. He also says that the life experienced in our surroundings is through our bodies. His philosophy is connected to the lived 
experience through bodily perceptions. A place is described as a social construct, which is an understood and experienced environment [12]. An individual's experience of a place is altered by the way he feels, the essence of mind and how he articulates the thoughts and emotions that alter one's experience in a place [13]. Lam brings to significance the presence of the body in being a central factor in our embodiment of the world [11]. Similarly, Ponty describes how he perceives things through his body [10].

According to Styhre, through phenomenology, a perception of a sense-sensitive technique and re-embodied organization can be developed [14]. However, it is crucial to apply sensory embodiment into practise to achieve a spatial experience. Mace highlights the significance of conducting documentation of site from the body, based on her theoretical antecedents [13]. Tran mentions the buildings of Peter Zumthor that are centred on gathering sight, smell, taste, touch and sound of the built environment [15]. E.g., include the Swiss Pavilion "Sound Box" at Expo 2000 in Germany. The Therme Vals is yet another significant work by Peter Zumthor, which offers a complete sensorial experience for its users.

It is to be noted that phenomenology is linked to subjective reality. One person's perception can be different from another person. By employing phenomenology in designing places, the quality of life in urban places can be improved. Different senses contribute to achieving sensual experiences within a place. According to Kuepers, sight, hearing, smell, taste, touch and other sensual experiences together are part of a mediating embodiment that breaks the boundaries between the outside and inside [16]. Tran adds to these by stating that one can behold, touch, and assess the world through space and time through their complete existence, which is also known as the multi-sensory experience [15]. In addition to the aforementioned, Kuepers also adds that within a shared, embodied place and time, bodies can be seen, heard, touched, and move or re-orient their perspectives with respect to the other body [16]. This shows the significance of orientation and movement in altering one's bodily experiences in a place.

Relevant literature studying phenomenology in a place as a methodology includes sensory charts based on atmospheres as well as a study on sensing and experiencing places Merleau [10] and Mace [13] \& [17]. Hence, methodologies from these relevant works of literature are adopted in the study.

\section{Materials and Methods}

\subsection{Research Aim}

This research aims at studying an urban place, which is a part of user's everyday lives. By engaging in the urban place and experiencing it through phenomenology, a comprehensive understanding of the role of bodily experiences on a daily basis can be understood.

\subsection{Research Question}

How different senses such as vision, sound, smell, touch as well as other attributes such as kinesthesia, fluidity, perception and so on can alter one's bodily experiences?

How does the functionality and design of a place affect one's spatial experience?

\subsection{Methodology, Methods \& Research Tools}

The methodology selected to experience an urban place is a qualitative-exploratory approach. By walking, observing, photographing, and mapping during different times of the day, the multi-faceted sensualities of the urban place are uncovered. Moreover, a sensory slider is used as a tool for the study based on the chart by Mace [17]. Further, existing $\&$ proposed atmospheric conditions within the place are evaluated. To get a comprehensive understanding of how spatial experience is affected, behavioural factors, noise levels, and functionality of places were addressed. Thus, data for existing atmospheric conditions should be produced and recommendations should be given to achieve a complete sensorial experience. By doing so, the role and significance of sensorial experience within an everyday context can be highlighted. This will also bring forth awareness among designers, encouraging one to engage in enabling deeper meanings into spaces.

The primary method to conduct the study is using a case study method. The researcher by itself is the instrument to conduct the study. The tool involved in the study includes using a "sensory slider chart" by Mace [17] to map the experiences at different zones. Moreover, a behavioural and noise level mapping was conducted based on the functionality and division of the zones [18]. The limitation of the study includes being amidst the COVID-19 pandemic and not being able to engage with different users and experience sites for a longer duration.

\section{Data Analysis}

\subsection{The Site}

The site selected as the case study is Riffa Walk Park in East Riffa (figure 1). The site is selected for study as the park is used for walking regularly by the neighbouring residents as well as due to the prominence of its location, connecting different districts. Though the park is regularly used for walking, exercising, and playing, the park lacks relevance. As the park is located in a special use zone, the site offers the opportunity to design an urban place full of life. Further, social values and connectivity are added to residents of three prominent districts. Hence, the study intends to explore the possibilities of engaging and experiencing this urban setting. 


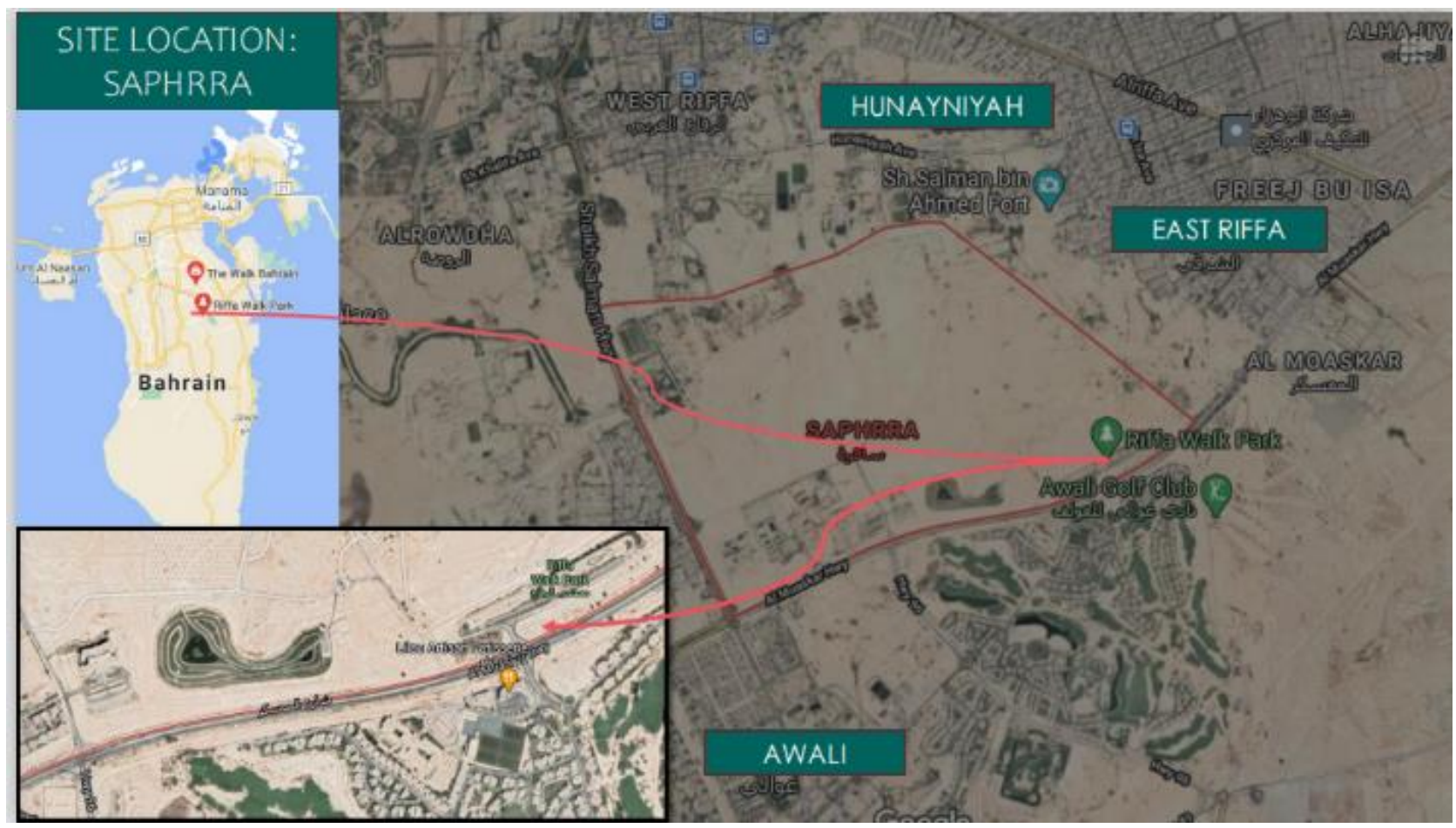

Figure 1. Riffa walk park, located in East Riffa in the Southern Governorate of Bahrain

\subsection{Macro \& Micro Analysis}

The Riffa walk park is located in East Riffa in the Southern Governorate of Bahrain (Figure 1). The primary reason for selecting this location for the study is that it is situated adjacent to a prominent highway in Bahrain known as the Al Muaskar Highway, which connects different regions of the country. The selected site is located between East Riffa, Hunaiyniah, and Saphrra. Moreover, the site offers various opportunities for designing an urban place full of life since the park is located in a "special use" zone. Existing facilities of this site include hospital, universities and schools. The Hunayniah oasis phase 1 and phase 2 are ongoing projects adjacent to the park. These act as ancillary facilities to the park, or vice-versa.

The site does not have any retail or cultural buildings. Additionally, the site is being used informally by camping visitors [19]. In addition, the sidewalks adjacent to the highway of this area are regularly used by cyclists and joggers. Despite all the activities being done in the park such as residents of the neighbourhood walking, exercising, and playing regularly, the park lacks relevance.

\subsection{Justification of Riffa Walk Park as an Urban Place}

The site is selected for various reasons (Figure 1). This includes the prominence of the zone as it connects different highways, its lack of amenities, basic facilities, functionality and usability. Moreover, a proposed Hunaiyniyah oasis and sanctuary is located adjacent to the selected site. The Park also adds to social values and connectivity to residents of three prominent districts. In addition, walkability from park to oasis and amenities surrounding adds to the economic values of the country by attracting tourists passing by a prominent highway. Moreover, as the site is in a 'special use' zone, it offers an opportunity to design an urban place full of life. Lastly. the region being a dry vacant land with no agriculture, landscaping or access adds to the necessity to study.

\subsection{Overview of the Study}

To manage my field study, the site was divided into 6 different zones. It is divided according to the size of the area and the type of activities. Zone 1 includes land with little vegetation on the outskirts and sitting spaces within the park. Zone 2 is the central zone that includes security and recreational facilities. Zone 3 includes sandy land with kids' play facilities. Zone 4 comprises land with greenery and shaded sitting spaces. Zone 5 consists of a row of palm trees, landscaping, and finally, Zone 6 which is the entrance walkway from the parking consists of wide stairs and ramps, in the form of a horizontal strip. 


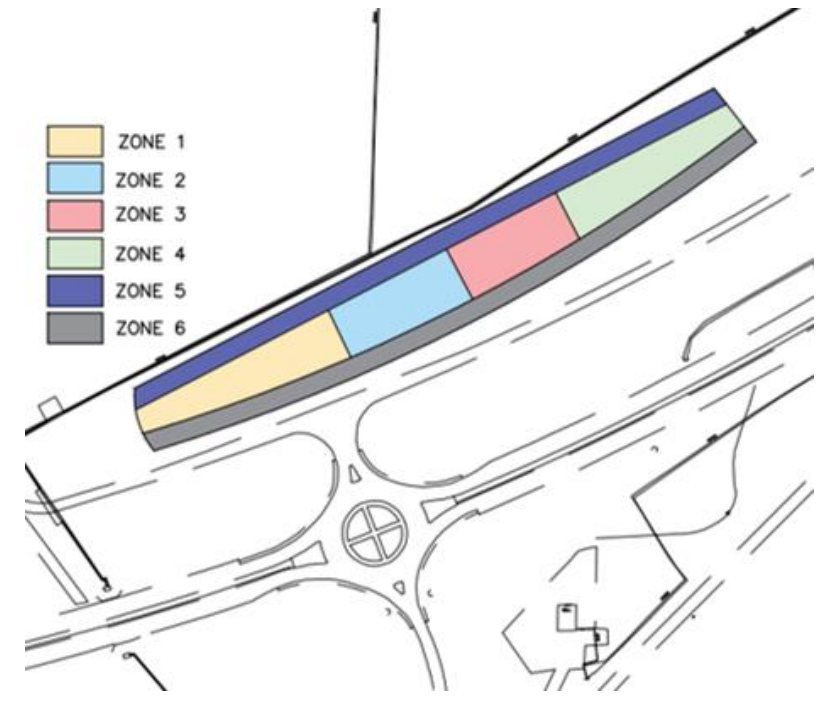

Figure 2. Division of site into 6 different zones
According to the bodily analysis of Zone 1, the main physical observation were lots of palm trees, direct sunlight hitting on the face while walking, which lead to the need to re-orient from the followed path myself. The zone also consisted of dusty sand, soft shrubs, the sounds of vehicles on the highway, soft sand and stones, and decorative old tires placed on the sand to create a colourful and place, attracting children and youth. The decorative tires also represent the shape of ancient wells, touching upon the history of the place that is close to the ancient natural springs. Though these tires were places that could be touched, there were benches under a canopy that couldn't be used to respect the COVID-19 protocols. As this zone is mostly used by people who are walking, there were relatively fewer activities going on. The movement was quite moderate; there weren't any hindrances to it. Most people walked through the track; rarely people crossed through the sandy area (Figure 3)

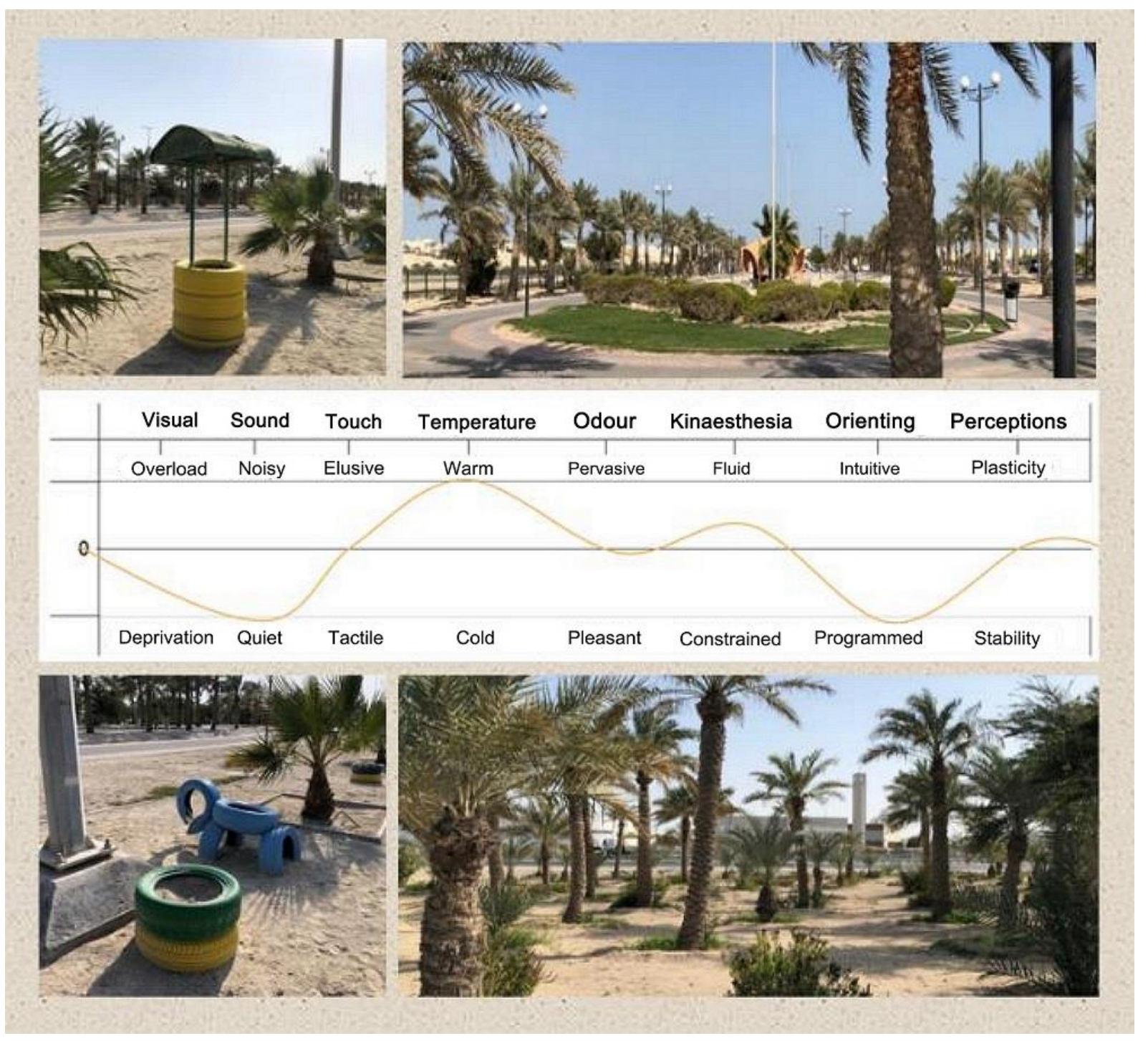

Figure 3. Bodily analysis observed in Zone 1 


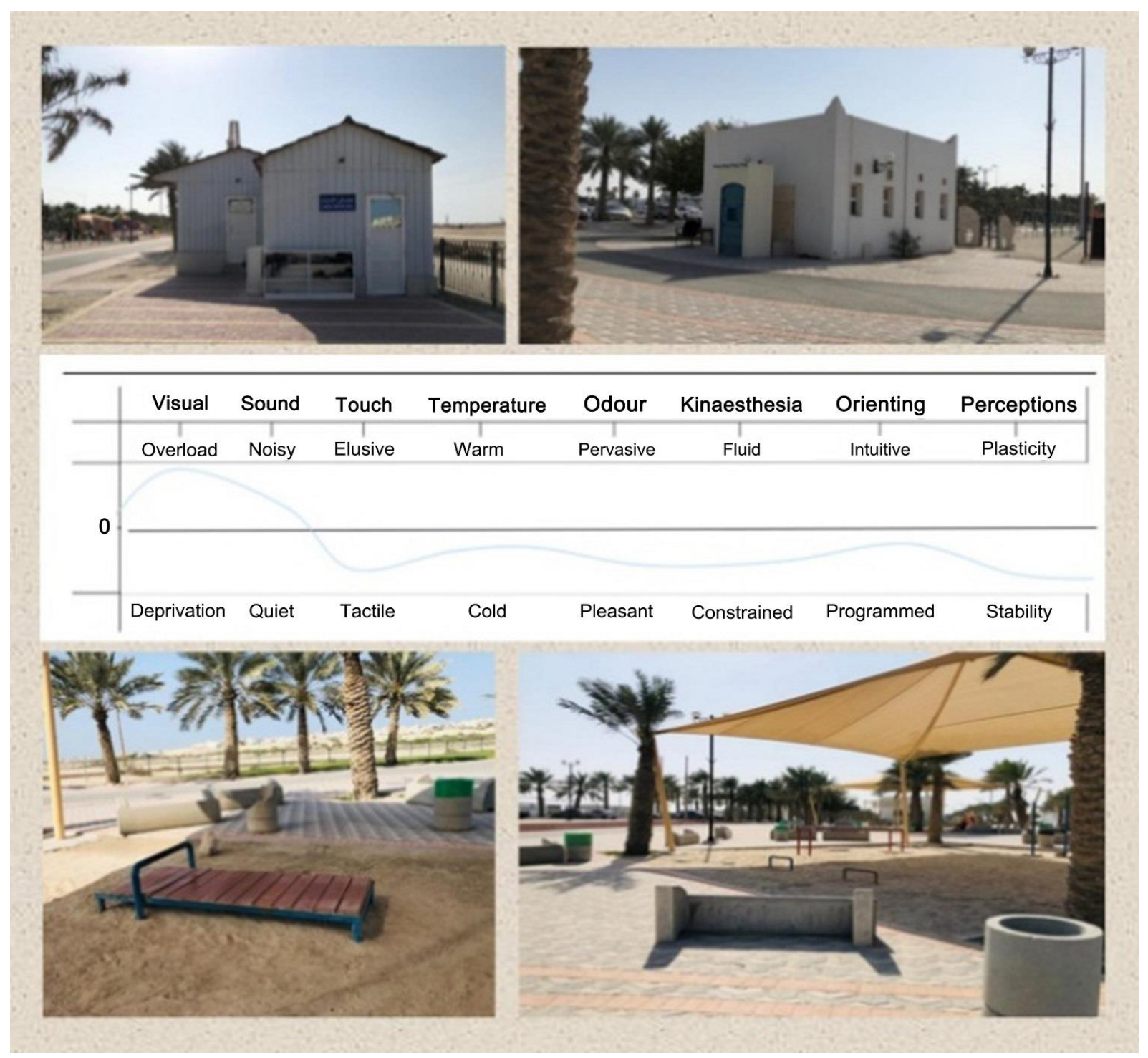

Figure 4. Bodily analysis observed in Zone 2

According to the bodily analysis of Zone 2 (Figure 4), the main physical observations were the security building, ablution area, prayer rooms, shop, and restrooms. There was a recreational area with a shaded canopy, where people did different exercises.

A mixture of pavement textures was observed. The place was quite noisy as there was the sound of people walking in and people exercising. Moreover, the zone provided warmth and shading and had visually pleasing colours blending with the surroundings. However, again the benches were flipped downwards to avoid usage amidst the pandemic. As a result, it wasn't easy to spot a place to sit. Moreover, the movement was quite constrained within the shaded central zone. Several structures were placed close to each other, making it difficult for those who wish to cross from one track to the opposite track. On the other hand, according to the bodily analysis of Zone 3, the main physical observations were pleasant odour, cool breeze, soft sand, and sounds of children. This zone consists of kids' play areas and sitting spaces. The kids' play area includes swings, see-saws, and playsets. The children are seen playing on the playsets. 


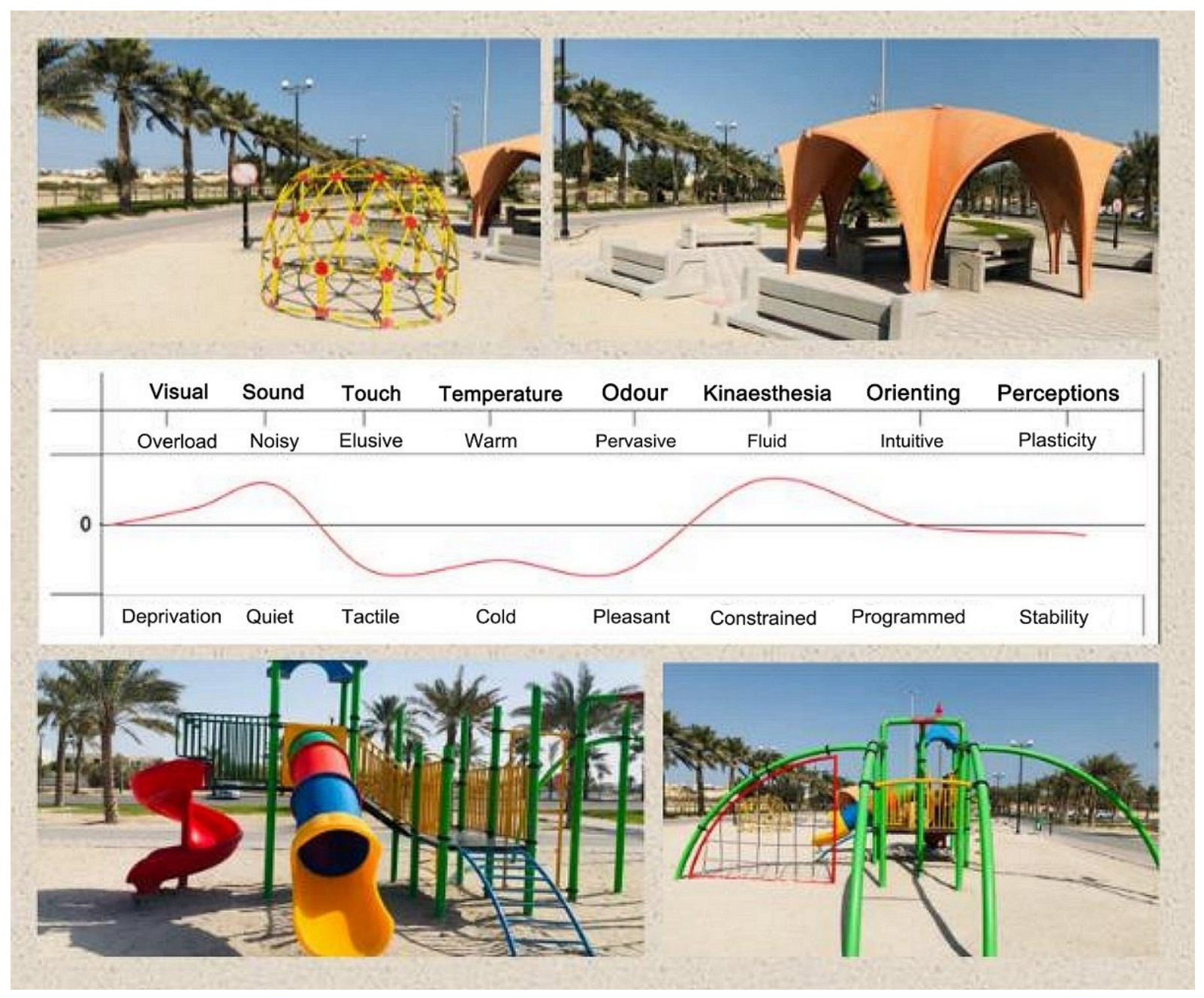

Figure 5. Bodily analysis observed in Zone 3

However, they are not allowed to use the swings as they are tied up to the rod. The area was colourful and visually attractive, especially to the kids; with playsets of primary colours. The movement in this zone was the smoothest due to the orientation of the kids' play structures. There was sufficient space to move from one track to another or even get into another zone. The sound of children playing and having fun ignited the spirits (Figure 5). 


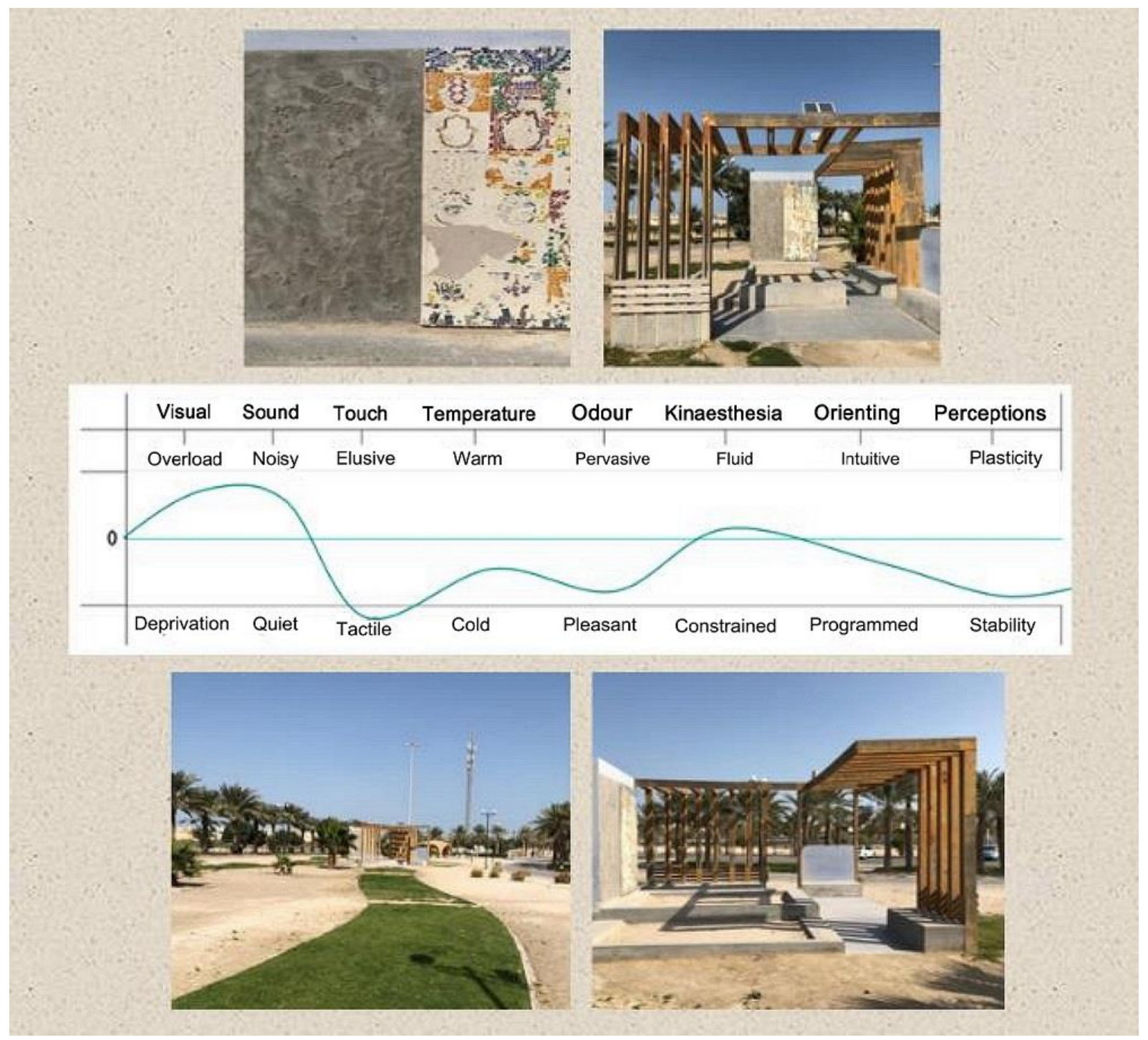

Figure 6. Bodily analysis observed in Zone 4

However, based on the bodily analysis of Zone 4 (Figure 6), the main physical observations include a shaded structure with panels and benches integrated with it. There was also a change in texture for the walkway leading to the structure, sand to grass. The structure also included a zone within which had a wall that was divided into two; 1 with exposed concrete and 2 with designs in colourful mosaic tiles. This provided a unique tactile experience. Moreover, the patterns of shadow cast during the sunset through the panels produced a tranquil and sensual experience to rummy trees fulfilled the sensory experience. The movement was quite moderate. In addition, the sound of birds chirping from the nearby and to a point insignificant as the place produced immense pleasure in terms of perceptions, welcoming one to get there. 


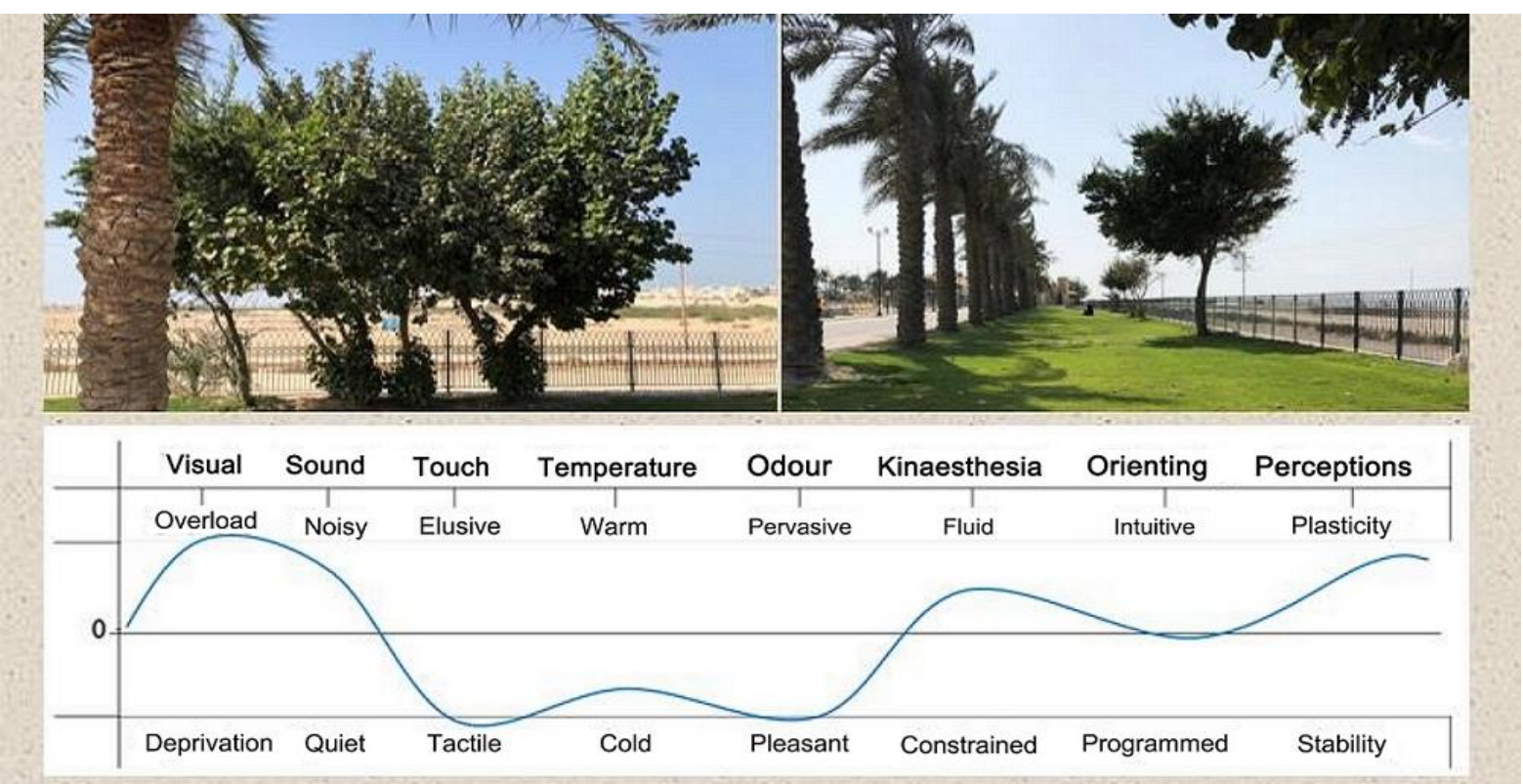

Figure 7. Bodily analysis observed in Zone 5
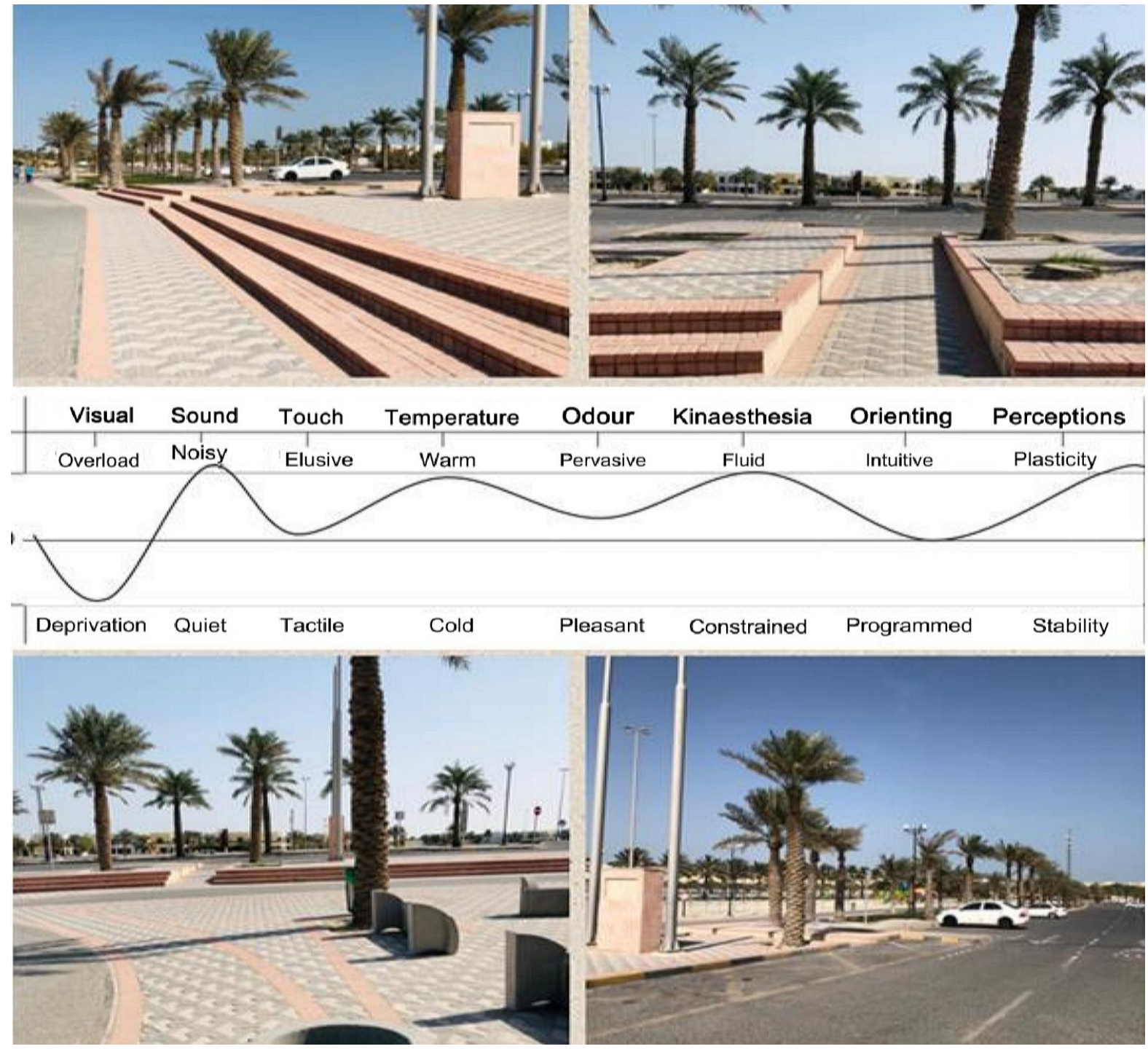

Figure 8. Bodily analysis observed in Zone 6 
The observations of Zone 5 (Figure 7) included a grass walkway and wet area. This area has a row of palm trees and other flowering trees. As it is restricted to walk on top of the grass, some visitors sit informally for a while on this texture. On sitting and closely observing the surroundings, a magnificent sunset was observed, with the sound of birds chirping and dried leaves fallen from the trees touching the feet. It is a place where one can peacefully sit and enjoy solitude at its best.

Finally, the physical observations of Zone 6 (Figure 8) based on the bodily analysis was a long strip of stairs and ramps from the parking welcoming the visitors. The entranceway did not have any hindrance and was very interesting. The ramps were designed in such a way that it was right in front of the parking for special use. The design and material of the trash cans were blended with the benches, creating a feeling of oneness. Moreover, it is a visually pleasing environment with an elevation of palm trees arranged in a row, blending into the colour scheme and nature.
However, the sound of vehicles speeding on the highway besides was overpowering. There were informal sellers and ice cream vans spotted in this zone, adding more meanings and memories to the place.

\section{Achievements \& Results}

Through sensual bodily experiences, one can achieve a complete and meaningful experience within an urban place. The study helped to identify how people perceive a place with a natural attitude. However, this experience is altered by factors such as movement, behaviour and activities through Visual sense, Sound, Touch, Temperature, Odour, Kinesthesia, Orienting and Perceptions (Figure 9). Moreover, Noise levels contribute significantly to the spatial environment. Based on the methodology followed, a list of behaviours and noise levels at different timings were noted as per the phenomenological tool used by Mace. (Table 1).

Table 1. Behaviors and Noise Level, Author (2021)

\begin{tabular}{|c|c|}
\hline Behaviors & \multicolumn{2}{|c|}{ Noise Levels } \\
\hline Driving & People doing exercise \\
\hline Walking & Noise from highway \\
\hline Running & Sound of birds \\
\hline Play & More people to walk \\
\hline Sitting on grass & Children playing, bicycling \\
\hline Standing in queue & Camping informally \\
\hline Family gathering & More vehicles \\
\hline
\end{tabular}

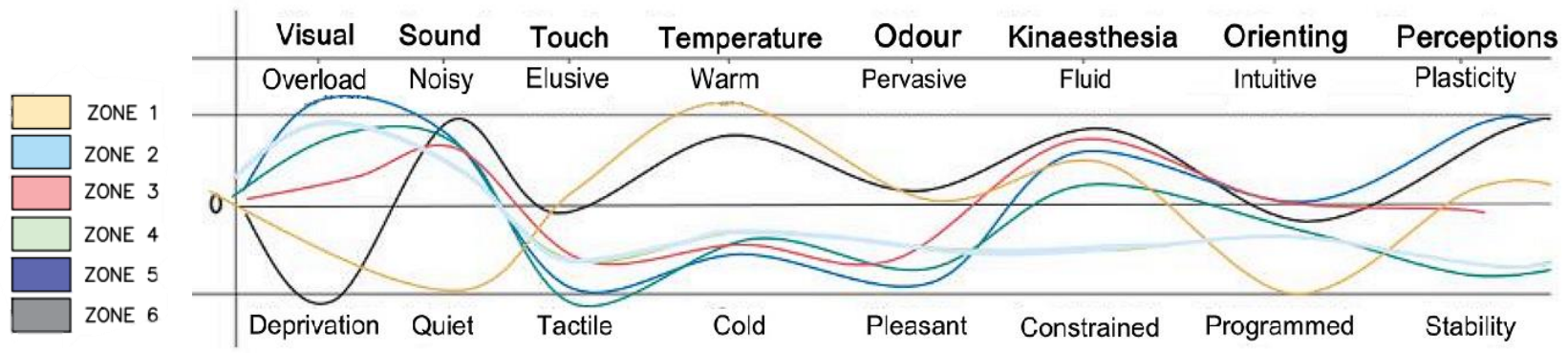

Figure 9. Sensory Slider Chart of Riffa Walk Park, Author (2021). 


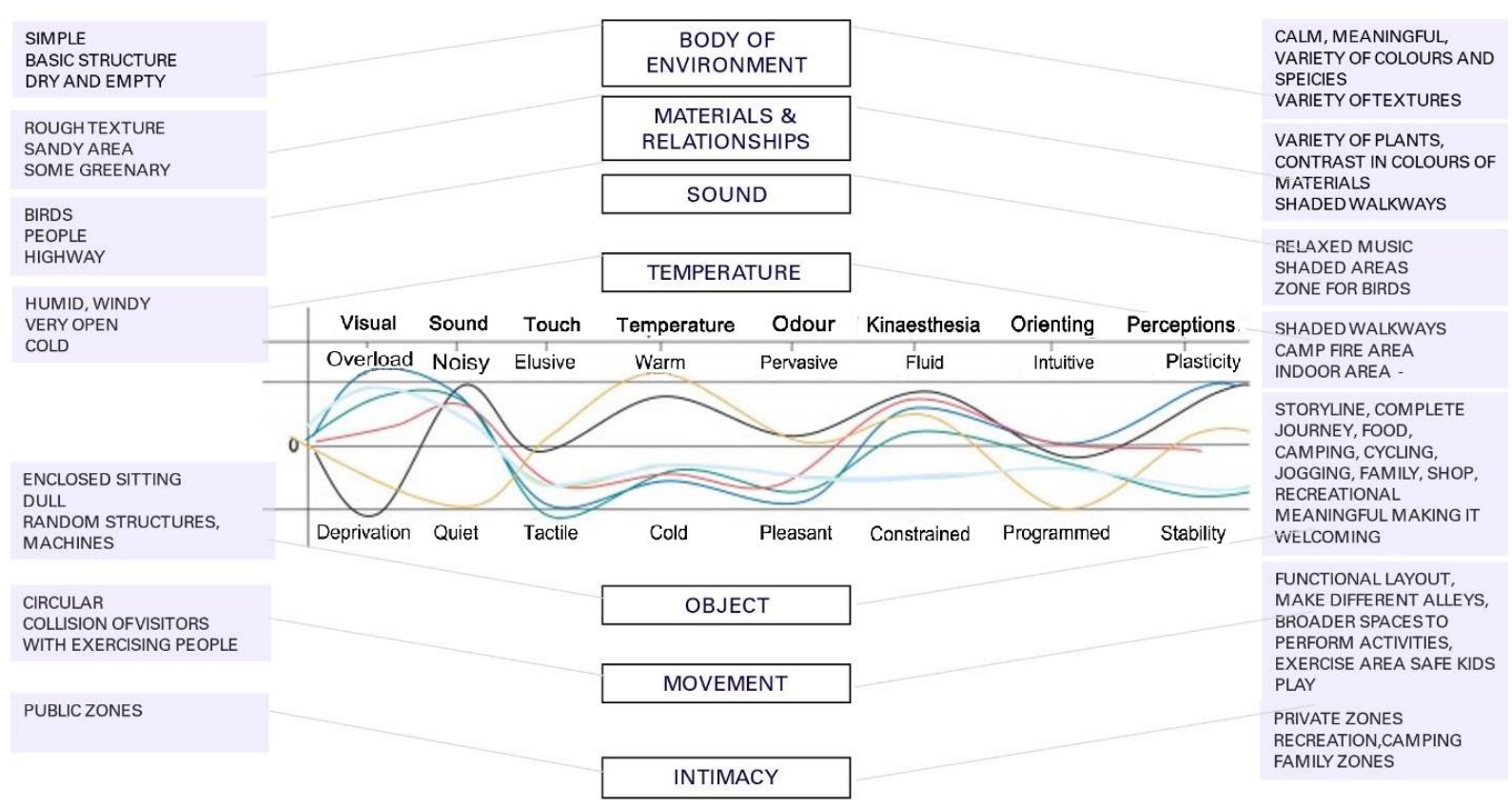

Figure 10. Existing vs proposed urban open space conditions, Author (2021)

\section{Discussion}

Based on the methodology followed by Mace, a chart of existing factors and proposed factors were listed based on attributes such as Body of Environment, Materials \& Relationships, Sound, Temperature, Object, Movement, and Intimacy [17]. By representing the existing urban open space conditions, a new set of environmental conditions were produced as below; Post the pandemic of Covid-19; the designers need to approach the spaces in a very cautious and thoughtful manner. The spaces could be designed by paying attention to the location of its elements, the way the elements have been grouped, and their orientation. Data which is both subjective and objective is essential, as the public lives and experiences the place. It is important to have an understanding of the requirements and the experiences of the user and to design the spaces in such a way that the place could be meaningful for the public. Designing spaces with such an attitude further develops memories in users' minds, enabling unique identity for that space in their minds. (Figure 10).

\section{Conclusion and Recommendation}

To conclude, this research has enabled us to acquire new insights into the perceptions of urban places and public parks. It also helped to understand the perceptions of the amenities included in the space which people experience with a very natural attitude and perceptions regularly. Moreover, the study was also beneficial to learning and understanding how the use of a sensory slider could be successful in evaluating the experiences that people have about the place. Gathering within the parks was limited, and considerations had been undertaken to reduce contact with the surfaces in the location due to the COVID-19 pandemic. The role of sense of touch over visual senses could be understood along with the understanding of the human bodily experiences and how movement and other factors can be adjusted. The role of different senses and how they can develop a spatial experience together could also be learned and understood through the study.

Finally, the research recommends that Phenomenological tools such as the sensory slider chart, behaviour \& noise levels be used and the existing atmospheric conditions be analyzed to enable new atmospheric conditions can help urban designers and architects in enabling places that are meaningful and multi-sensorial in future outdoor space designs. Moreover, designing an urban place considering the bodily experiences can mark a unique experience that creates a memory within the user and provides an identity for the place. Employing bodily experiences and phenomenology in urban places can enable users to enjoy spaces more meaningfully, especially amidst the COVID-19 pandemic which requires users to maintain social distancing in a public realm. Thus, designing spaces considering different levels of senses such as Visual sense, Sound, Touch, Temperature, Odour, Kinaesthesia, Orienting and Perceptions can foster a complete spatial experience within a place. Future studies can involve collecting data from different users within a place to get an in-depth understanding of user perception, especially amidst COVID-19. 


\section{Acknowledgments}

This research did not receive any specific grant from funding agencies in the public, commercial, or not-for-profit sectors.

\section{Conflict of Interests}

The authors declare no conflict of interest.

\section{REFERENCES}

[1] Janahi, D., Marhoon, Z., Elghonaimy, I., The use of attractive lights to encourage the public of using the outdoor areas to control the spreading of COVID 19, 3rd Smart Cities Symposium, 21-23 Sept 2020, paper id: 1941570677160, https://www.3rd-smartcities-2020.com/, DOI: 10.1049/icp.2021.0969, ISBN: 978-1-83953-522-2

[2] Elghonaimy, I. Visual pollution phenomena and sensitivity of residences in heritage city centers Case of: Old district of Manama city, Kingdom of Bahrain. International Journal of Contemporary Urban Affairs, 3(1), 175-190. ISSN: 2475-6156 (2018). (print), ISSN: 2475-6164 (online). Available at: http://ijcua.com/index.php/ijcua/article/view/ 125/68, https://doi.org/10.25034/ijcua.2018.4694, article URL: http://ijcua.com/index.php/ijcua/article/view/125/68

[3] T. Eagleton, Literary Theory: An Introduction, Blackwell Publishing, UK, 1983., https://doi.org/10.1177/089692058 601300410

[4] D. Seamon, Christopher Alexander and a Phenomenology of Wholeness, Environmental Design Research Association (EDRA), Sacramento, 2007., https://doi.org/10.3390/urban sci3020046

[5] C. Alexander, A Pattern Language, Oxford University Press, New York, 1977., (53) (PDF) A Pattern Language Towns, Buildings, Construction | LIN HONG - Academia.edu

[6] C. Norberg-Schulz, Genius Loci: Towards A Phenomenology of Architecture, Rizzoli, New York, 1980. https://marywoodthesisresearch.files.wordpress.com/2014/ 03/genius-loci-towards-a-phenomenology-of-architecturepart1_.pdf

[7] D. Seamon, Phenomenology, Place, Environment, and Architecture: Review of the Literature, 2002. https://www.researchgate.net/publication/238798666_Phen omenology_Place_Environment_and_Architecture_Revie w_of_the_Literature

[8] J. Pallasmaa, The Eyes of the Skin: Architecture and the Senses, Chichester: Wiley-Academy, UK, 2005. https://arts.berkeley.edu/wp-content/uploads/2016/01/Palla
smaa_The-Eyes-of-the-Skin.pdf

[9] J.Pallasmaa, Architecture and Biophilic Ethics, Cloud-Cuckoo-Land, International Journal of Architectural Theory, Vol. 22, No. 36, 57-69, 2017, https://cloud-cuckoo.net/fileadmin/issues_en/issue_36/artic le_pallasmaa.pdf

[10] M. Merleau-Ponty, Phenomenology of Perceptions, Routledge, New York, 2013. https://doi.org/10.4324/978 0203994610

[11] A. Lam, The Bodily Perception of Details, 98th ACSA Annual Meeting Proceedings, Rebuilding, 121-127, 2010. ACSA.AM.98.15.pdf (acsa-arch.org)

[12] H. Lefebvre, The Production of Space, Blackwell Publishing, Oxford, 1991. https://myweb.fsu.edu/jjm09f/1 \%20Final\%20Project\%20Materials/lefebvreintro.html

[13] V. Mace, A phenomenological approach to primary research in Spatial Design, Spark: UAL Creative Teaching and Learning Journal, Vol.1, No. 2, 115-121, 2016. View of A phenomenological approach to primary research in Spatial Design | Spark: UAL Creative Teaching and Learning Journal (arts.ac.uk)

[14] A. Styhre, The (re)embodied organization: Four perspectives on the body in organizations, Taylor \& Francis Online, Human Resource Development International, Vol. 7, 101-116, 2004 https://doi.org/10.1080/13678860320001 50578

[15] D. Tran, Phenomenology method of making a place, MATEC Web of Conferences, 193, 2018, https://doi.org/10.1051/matecconf/201819304021

[16] W. Kuepers, Phenomenology of the embodied organization: The contribution of merleau-ponty for organizational studies and practice, Palgrave Macmillan, UK, 2015, DOI: $10.1057 / 9781137460554$

[17] V. Mace, Sensing the Urban Interior, [in]arch conference, Universtitas Indonesia in Depok, Jakarta, Indonesia, 2014., (53) (PDF) Sensing the Urban Interior | Valerie Mace Academia.edu

[18] Elghonaimy, I., Street furniture influence in revitalizing the Bahraini identity, International Journal of Contemporary Urban Affairs IJCUA, 4(1-2), approved for Publishing' date 2019-07-13, Publisher: Alanya Hamdullah Emin Paşa Üniversitesi, (2020) http://www.ahep.edu.tr, ISSN 2475-6156 (print), ISSN: 2475-6164 (online). Available at: https://ijcua.com/index.php/ijcua/article/view/147, DOI: https://doi.org/10.25034/ijcua.2020.v4n1-2.

[19] Elghonaimy, I., Al-Haddad, M. H. Towards reviving the missing noble characteristics of traditional habitual social life: "Al-Farej "In Kingdom of Bahrain. International Journal of Contemporary Urban Affairs IJCUA, 3(2), 35-46. ISSN: 2475-6156 (print), ISSN: 2475-6164 (2018) (online). Available at: https://ijcua.com/index.php/ijcua/article/view /97, DOI: https://doi.org/10.25034/ijcua.2018.4699. 